\title{
A la recherche du temps perdu - epilogue to the Minkowski Award lecture 1974
}

\author{
E. Cerasi \\ Department of Endocrinology and Metabolism, Hebrew University Hadassah Medical Center, Jerusalem, Israel
}

Key words: Aetiology of Type 2 diabetes; pre-diabetes; low insulin response; mechanism of insulin release; islet cyclic-
AMP; time-dependent effects of glucose; insulin release by DNA transfection.
Most scientists, I am sure, once middle-aged get a feeling of frustration which is unrelated to their own degree of success or failure in academic life, but rather due to the essence of research. Indeed, the fact that knowledge is a purely dialectic process, an endless spiral, makes the situation of the researcher quite an ambiguous one. Whereas each time his contributions raised knowledge to the next level of the spiral, and he may feel satisfaction and reward, he cannot fail to realize after some years of perspective that he will never reach his target, that the spiral is endless, that although he may be contributing to our "cultural heritage" he is not very different from the squirrel in the wheel. $\bar{A}$ Chinese friend, a person with his two feet solidly planted on the ground, asked me once what I do for a living. I answered that I am a doctor and a researcher, looking for the cause of diabetes. "Did you find it?" "N-no, not yet." "How long have you been looking for it?" Blushing, "Well, almost 20 years". "Good Lord! Why are you wasting your time? Do something useful!" I cannot help realizing that there is some foundation to the remarks of my friend; my only defence is that I am not capable of doing something else for a living. So this review, which is supposed to summarize my research since I was awarded the Minkowski Prize in 1974, may not seem very different from the review published in 1975 [1] which summarized the research of my first decade in diabetes. But, after all, the Chagall paintings of the $80 \mathrm{~s}$ are not very different from those of the $20 \mathrm{~s} .$. .

\section{Low insulin responders}

I entered the field of diabetes with the observation that the initial insulin response to glucose is markedly impaired not only in patients with diabetes of all severities, but also in a segment of the normal population [2]. Twenty-two years later I remain firmly convinced that the basic defect in diabetes is indeed the secretory deficiency of $\beta$ cells. This idea has been challenged over the past decade, especially since the concept of insulin resistance made its appearance and it was demonstrated that most Type 2 (non-insulin-dependent) diabetic patients show reduced biological response to insulin [3]. The belief that insulin resistance is the main pathogenic factor in Type 2 diabetes originated from the fact that these patients usually show substantial plasma insulin levels, both fasting and following meals or ingestion of glucose. To my mind, the confusion created by the observations of supra-normal or normal insulin responses in Type 2 diabetes emanates from experimental designs unattentive to the basics of $\beta$-cell physiology. Therefore I believe a short discussion of the methodology of the assessment of $\beta$-cell function in vivo is warranted (for a full discussion, see [4]).

Partly out of tradition, partly because it is believed to be more physiological, most investigators use an oral glucose load to assess $\beta$-cell responsiveness. A response can be evaluated only if the strength of the stimulus employed to elicit it is known. For insulin secretion the stimulus is obviously the blood glucose level. This obvious fact is seldom remembered. In the specific example of oral administration of glucose, the situation is complicated by the strong amplification of the glucose effect on $\beta$-cells by gut "incretins" [5]. Therefore, to quantify the insulin response, one must know what to expect from a given elevation of the blood glucose in this highly amplified, multiplicative synergistic system of insulin secretion. Comparing the plasma insulin levels of Type 2 diabetic patients and control subjects during an oral glucose tolerance test or meals and stating that the levels in the patients are higher is meaningless, unless it 


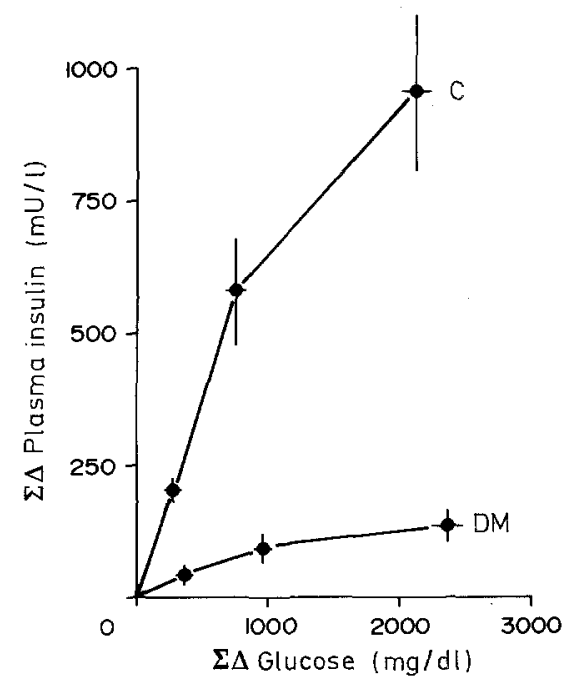

Fig. 1. Dose-response relationship of glucose-induced insulin response in 29 control subjects (C) and 18 Type 2 diabetic patients (DM). Intravenous glucose tolerance tests were performed with 0.1, 0.3 and $0.9 \mathrm{~g} / \mathrm{kg}$ glucose, respectively, and blood glucose and plasma insulin levels integrated over $60 \mathrm{~min}$. Horizontal bars denote the SEM of the glucose, the vertical bars that of the insulin values measured

is shown that the controls secrete less insulin under identical hyperglycaemic conditions. From early doseresponse studies we calculated that elevation of the peak plasma glucose concentration by $1.5-2 \mathrm{mmol} / 1$ during an oral glucose tolerance test was sufficient to double the insulin response in normal subjects [6]. From the same study, it was obvious that the dose-response curve of glucose-induced insulin release during the oral glucose tolerance test was markedly depressed in mild Type 2 diabetes [6]. Thus in every state of hyperglycaemia a seemingly normal insulin curve during an oral glucose tolerance test in reality reflects a severely deficient insulin response. To my mind there is no alternative to dose-response studies for characterizing the $\beta$ cell responsiveness to oral glucose. These studies are definitely time-consuming, difficult to perform and not without their own problems of interpretation; but rather that than the systematic misreading of the insulin data that has dominated diabetes research for the past two decades. A similar problem is the issue of glucose "specificity" of the deficient insulin response in Type 2 diabetes. Indeed, it has been said that the insulin response to arginine or glucagon is normal in these patients [7]. What is forgotten is that hyperglycaemia induces strong amplification of the $\beta$-cell stimulatory signal of these agents. Thus, in normal subjects clamped at a moderate hyperglycaemic level $(9.3 \mathrm{mmol} / \mathrm{l})$, the insulin response to arginine was augmented sixfold, and therefore mild diabetic patients with a similar degree of fasting hyperglycaemia had a "true" insulin response to arginine that was only $10-15 \%$ of normal [8].

If glucose is administered intravenously the problem of synergistic interactions with gut hormones does not exist. It is therefore easier to study the quantitative effects of glucose on insulin release when the intravenous glucose tolerance test, or its variants, is used. Admittedly, a peripheral vein is not the physiological port of entry for glucose, but how physiological is a 75 - or 100 -g glucose drink on an empty stomach?

It has been shown repeatedly that in Type 2 diabetes the insulin response to intravenous glucose is severely impaired [9]. Dose-response studies performed in the 1970s suggested to us that this impairment reflected a decrease in $\beta$-cell sensitivity to glucose, since we had the impression that very high blood glucose concentrations could elicit substantial responses in diabetes [10]. This may be true for second phase insulin release. A more recent study, where the glucose dose-dependency of first phase insulin release was compared in weight-matched control subjects and in mild Type 2 diabetic patients, clearly demonstrated that the maximal capacity of $\beta$ cells to respond to glucose was reduced by $80-90 \%$ in the patients (Fig. 1), without evidence of a right-shift of the curve $[11$, R. Nesher et al., unpublished observations].

Over 20 years of experience with hundreds of intravenous glucose challenges I have seen few exceptions to the rule of deficient insulin response in subjects with fasting hyperglycaemia, be it of a minimal degree. It is often argued that the intravenous glucose tolerance test does not reflect everyday life glucose homeostasis, which is true; nevertheless it discloses with high sensitivity the functional impairment of the islet apparatus. There is, therefore, no question in my mind that $\beta$-cell function is substantially reduced in Type 2 diabetes. Interestingly enough, the diabetic $\beta$ cell seems to retain some of the modulatory functions of insulin release. As an example, the capacity of the insulin response to glucose was threefold higher in obese diabetics matched for the degree of hyperglycaemia with lean diabetic patients. In normoglycaemic subjects with an identical degree of obesity, insulin release was also threefold higher than in lean controls [11]. Similarly, the potentiating effect of priming with glucose seems to be normal in diabetic subjects (see below).

In the 1960 s we made the observation that the decreased insulin response to glucose, similar to that in glucose intolerant subjects, was also seen in some healthy individuals $[2,12]$. We called such subjects "low insulin responders". The prevalence of "low insulin responders" is difficult to establish since, when control groups were screened with a glucose infusion test, no evidence for bimodal distribution of the insulin response was found $[13,14]$. Therefore no strict lower limit for insulin response could be established (the cut-off point given in some of our earlier studies must be taken with a pinch of salt!). Nevertheless, judged from the distribution histograms of a computer parameter describing the glucose sensitivity of the $\beta$ cell, there was complete overlap between the insulin responses of $90 \%$ of patients with mild Type 2 diabetes and $20 \%$ of weightmatched control subjects [14]. Thus, the prevalence of 

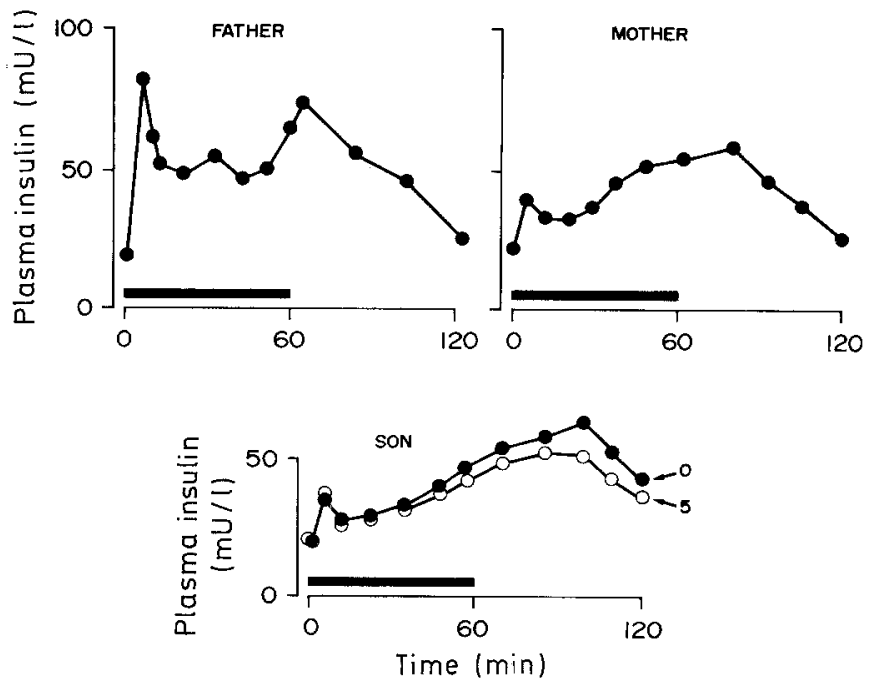

Fig. 2. Plasma insulin response to glucose infusion in a family. Glucose was given intravenously as $0.5 \mathrm{~g} / \mathrm{kg}$ bolus followed by $20 \mathrm{mg}$. $\mathrm{kg}^{-1} \cdot \mathrm{min}^{-1}$ for $60 \mathrm{~min}$ (horizontal bar). Note the similarity between the insulin responses of the mother and son (both "low responders"). Several tests were performed in the son, the first being marked by $(-0)$, the second 5 years later $\left(\mathrm{O}_{-} \mathrm{O}\right)$. One year later the son developed Type 1 diabetes

"low insulin responders" might be as high as $20 \%$. In one study [15], the plasma glycerol and non-esterified fatty acid responses to muscular exercise were found higher in "low insulin responders" than control subjects (although not to the extent seen in insulin-treated diabetes), suggesting that despite normal glucose tolerance there may be metabolic consequences to the reduction of insulin secretion. However, the cardinal question is whether a low insulin response predicts future development of Type 2 diabetes.

In 1963 [2] we suggested that "low insulin responders" might be "pre-diabetic" individuals. With a 20-year perspective, expecting a definite answer would be a legitimate request. Unfortunately our studies were not initiated as a prospective population study, and the fact that I left Stockholm does not facilitate the evaluations. The following statements are based on a first report that was published in 1974 [16], and a recent paper by Efendic et al. [17] but with my own interpretation of the glucose tolerance tests. Of a total of 174 subjects with a normal intravenous glucose tolerance test and a normal insulin response to glucose infusion, 12 developed impaired glucose tolerance at some time during the follow-up period (7\%); none had fasting hyperglycaemia. Out of 77 "low insulin responders" with normal intravenous glucose tolerance at the initial test, 17 developed impaired glucose tolerance $(22 \%)$ and eight manifest diabetes $(10 \%)$, two of the latter now being on insulin treatment. Thus, the total risk of abnormal glucose metabolism was $32 \%$ in "low responders" versus $7 \%$ in "high insulin responders", diabetes being observed in "low responders" only. If one adds to this information the data of Kosaka's group [18] which showed that in
288 individuals with impaired glucose tolerance followed for 5-12 years, $29 \%$ of subjects who initially had a low insulin response progressed to diabetes versus $6 \%$ in subjects with normal to insulin response, it becomes evident that as a group "low insulin responders" definitely have an increased risk of developing diabetes. There is probably no answer to the question whether a low insulin response in a given subject really indicates that he will sooner or later develop diabetes. Obviously a $20 \%$ prevalence of low insulin response is much higher than the average diabetes prevalence; the difference in these prevalences diminishes markedly however if one considers the high occurrence of Type 2 diabetes in the elderly.

There is no need to stress the satisfaction with which I follow the recent revival of interest in first phase insulin response in subjects suspected to be "pre-diabetic" for Type 1 diabetes $[19,20]$. If the demonstration of a gradual reduction in insulin response in subjects with islet antibodies years prior to the appearance of hyperglycaemia is applicable to the ordinary patient with Type 1 diabetes, a low insulin response would become a marker of "pre-diabetes" not only for Type 2 but for all types of diabetes. No doubt we will witness many studies in this direction in coming years; and perhaps the anathema on the term "pre-diabetes" will be lifted now that it has entered the respectable field of diabetes immunology. Investigators interested in the correlation between immunological features related to Type 1 diabetes and $\beta$-cell function should, however, remember that a defective insulin response occurs in $20 \%$ of the control population (our "low insulin responders" were all islet-cell antibody-negative [G.F.Bottazzo and D. Doniach, unpublished observations]).

It is possible that the $\beta$ cell responds to any aggression by diminished insulin response to glucose, and perhaps the low insulin response of Type 2 diabetes is not different from that of pre-Type 1 diabetes, i.e. some as yet undefined factor inhibits the action of glucose. Our assumption, however, has been that in Type 2 diabetes, where the genetic component is dominant, the low insulin response is an inherited trait. This assumption was based on the following observations: (1) In monozygotic non-diabetic twins of diabetic patients, and in two families with Type 2 diabetes in several generations, the incidence of a low insulin response to glucose was very high $[21,22]$. (2) In children aged 7-16 years the distribution of the insulin response to glucose was similar to that found in adults, about $20 \%$ of children showing a low insulin response [23]. (3) In a large population study involving 155 families, where glucose infusions were performed, the insulin response was found to be genetically regulated [24]. This is illustrated with one family, where the similarity between the (low) insulin responses of the mother and one child is striking (Fig.2). (4) We have recently studied the dose-response relationship of glucose-induced insulin release in 10 non-diabetic adult offspring of two Type 2 diabetic parents. In most, the in- 

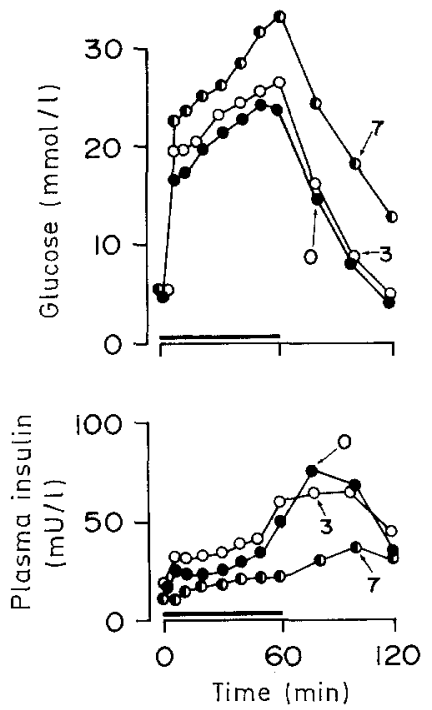

Fig.3. Plasma insulin response to glucose infusion in a "low responder". Test conditions as for Figure 2. The subject was followed for 7 years. While the insulin responses were similar at the initial test $(0)$ and 3 years later, (3) after 7 years (7) it was reduced and the glucose curve suggested impaired glucose tolerance. Some time later the patient developed moderate fasting hyperglycaemia

sulin response capacity was reduced, the distribution of the responses being significantly shifted to the left of the distribution in control subjects (C. Norynberg et al., unpublished observations). (5) It was shown that both in subjects with a normal insulin response and in "low responders", the insulin response was astonishingly stable over a period of 1-8 years [16]. Taken together, these observations would suggest that a low insulin response to glucose is indeed an inherited trait and that it occurs with a higher frequency in susceptible families. However, the situation may be less clear than what appears from the above statements. Indeed, a renewed workup of the data from our population study (after computation of the glucose infusion tests) showed that although insulin response is indeed under genetic control, heritability was high in the children while it was considerably reduced in the adults [25]. This may suggest that environmental factors gain an increasingly important influence on insulin release with increasing age. Type 2 diabetes being a disease that develops extremely slowly, there are too few longitudinal, serial observations of the insulin response during the evolution of the disease from pre-diabetes to clinical diabetes. Figures 2 and 3 give examples of lack of reduction and of gradual reduction in the insulin response prior to the appearance of clinical diabetes in two "low responders". I do not believe the present data permit us to answer the question whether insulin release is gradually (further) impaired in Type 2 diabetes as it apparently does in Type 1 diabetes.

So many studies have demonstrated insulin resistance in Type 2 diabetes [24-26] that it may seem heretical to question its role in the pathogenesis of the disease. Still, can one avoid wondering why, if insulin re- sistance is the main cause of Type 2 diabetes, only a minority of subjects with obesity and severe insulin resistance become diabetic? If, as results of treatment of Type 2 diabetes indicate [29], the insulin resistance is a secondary event, at what stage of diabetes does it appear? Most studies have been performed on patients with advanced fasting hyperglycaemia (13-14 mmol/l). We investigated recently [11]; R. Nesher et al., unpublished observations] a group of lean and obese Type 2 diabetic patients with mild hyperglycaemia (mean $9 \mathrm{mmol} / \mathrm{l}$ ) at their basal hyperglycaemic level, and used a non-steady-state protocol to establish dose-response curves for insulin-mediated acceleration of glucose disappearance. Bearing in mind that control subjects were normoglycaemic while the patients were hyperglycaemic, we could not demonstrate any difference in insulin sensitivity between weight-matched controls and Type 2 diabetic patients. Although not excluding sensitivity differences at physiological insulin levels [30], and accepting the effect of hyperglycaemia per se on glucose disposal [31], we still believe that such results exclude a primary role for insulin resistance in the pathogenesis of Type 2 diabetes. We could, furthermore, demonstrate highly significant correlations between the fasting plasma glucose level and equations describing the dose-response curves for glucose-induced insulin release and for insulin-induced glucose disposal. Analysis of these equations showed that $27 \%$ of the variance of the fasting plasma glucose could be explained by the insulin secretion, while insulin sensitivity contributed only to $4 \%$ of the variance [R. Nesher et al., unpublished observations]. This does not mean that insulin resistance plays no role in Type 2 diabetes. First, hyperglycaemia itself apparently influences post-receptor events and hence glucose clearance, thus augmenting the hyperglycaemia $[29,31]$. Second, it is quite obvious that in any state of insulin deficiency (as in "low insulin responders"), addition of insulin resistance cannot but induce a deficit in the bioeffect of insulin, leading to hyperglycaemia. This was shown experimentally in an animal model of Type 2 diabetes, the spiny mouse. Spiny mice (Acomys cahirinus) in the Jerusalem colony have a markedly reduced first phase insulin response to glucose but seldom become hyperglycaemic. When obesity was induced in Acomys by a hypercaloric diet, and severe insulin resistance established, the insulin response to glucose augmented only marginally, and as a consequence hyperglycaemia developed [32].

To summarize, I think that under normal conditions an islet is fully capable of coping with the load imposed upon it by the insulin resistance of, for example, obesity, by augmenting its insulin output severalfold. Therefore I do not believe that, except for extreme situations such as the existence of receptor antibodies, insulin resistance may by itself be a sufficient and primary factor for the pathogenesis of diabetes. Only when the responsiveness of the islet apparatus is reduced, perhaps through genetic factors, can insulin resistance increase the gap 
between the demand and the offer for insulin bioeffect, leading to hyperglycaemia. The lower the responsiveness of the $\beta$-cell, the easier would insulin resistance tip off the balance. However, below a secretory limit diabetes would probably occur without the help of additional factors.

\section{The physiology of insulin secretion}

Having convinced myself (hopefully also some of the readers) that the primary problem in diabetes resides at the level of the $\beta$ cell, I have less of a bad conscience in spending so much time and money on trying to understand how the release of insulin is regulated. Also in this field, I am afraid, I will not be able to state the opposite of every word I wrote in my Minkowski Lecture [1]. In fact, I realize that what my group has done during the past 10 years is to justify, with real data, the statements that I made so lightheartedly in 1975 !

I have always envied researchers who work with prolonged static incubations of islets, where the insulin release rate gives the impression of being uniform in time: they make life easy for themselves. It is common knowledge that during a constant stimulation, the rate of insulin release oscillates dramatically; I cannot help being fascinated by this phenomenon. The reason for the biphasicity of the insulin response is not clear. However, studies in man and in vitro suggest to us that glucose acts on insulin release in three distinct ways: (1) It initiates the chain of events commonly referred to as the stimulus-secretion coupling responsible for the acute secretion, and which is a sine qua non condition for the occurrence of release at any time. This action of glucose is very rapidly initiated, and is as rapidly reversed once the hexose falls below a threshold level. (2) Shortly after initiation of secretion, glucose generates a state of refractoriness in the $\beta$ cell, called time-dependent inhibition, that reduces the secretion rate despite ongoing stimulation. This inhibitory action persists after glucose is withdrawn. Although the $t^{1 / 2}$ of time-dependent inhibition is not known precisely, it is definitely of the order of several minutes and quite different from that of acute stimulus-secretion coupling [33-35]. (3) The third event, slower in onset, amplifies the insulin response with time, and thus is responsible for the late increase in the secretion rate [36-39]. We have named this phenomenon time-dependent potentiation; its $t^{1} / 2$ is also quite long. Based on several lines of evidence, we have postulated that the biphasic nature of glucose-induced insulin release is due to the expression of both time-dependent inhibition and potentiation on the acute stimulussecretion coupling with different time courses, the sum of these positive and negative inputs resulting in the characteristic oscillation of the secretion rate [40].

This emphasis on the biphasic nature of insulin release is not incidental. In Type 2 diabetes, first-phase insulin response is selectively diminished or abolished, while second phase release is usually retained until quite advanced stages of the disease $[2,9,41,42]$. A similar situation exists in Acomys cahirinus. At all stages of glucose intolerance, the spiny mouse exhibits decreased insulin response to glucose stimulation in vivo and in vitro $[32,43]$. Both in pre-diabetic and diabetic man, and in the spiny mouse, although acute insulin response to glucose is markedly diminished, the time-dependent potentiating effect of the hexose is retained [44, 45]. Indeed, we showed recently with a perifusion system that by inducing time-dependent potentiation in islets of $\mathrm{Ac}$ omys we could correct the kinetics of insulin secretion, re-establishing normal first-phase response [45]. From the above, it seems clear that the cellular mechanisms for acute stimulus-secretion coupling of glucose-induced insulin release, and those for time-dependent potentiation cannot be identical. Since the islets of Type 2 diabetic patients and those of spiny mice contain normal amounts of insulin $[44,45]$ and time-dependent potentiation may restore a normal release, it could be concluded that the basic defect of diabetes (i.e. the inability to secrete first phase insulin) must be of a functional nature and hence amenable to correction.

The release of insulin, like other exocytotic events, is calcium-dependent. There is consensus that glucose elicits its acute effect on insulin release by elevating the cytosol concentration of calcium ions [47]. Hellman et al. [48-50] have recently demonstrated convincingly by direct measurements of the cytosol calcium activity with quin 2 that glucose increases the influx of calcium through the plasma membrane into the cytosol and also from the cytosol to mitochondria, secretory granules and other storage compartments. This unitary action of glucose (stimulation of calcium movements from the outer face of membranes inwards) results in a dual effect on cytosol calcium: initially a reduction due to sequestration of the ion, followed by increase due to the more important influx from the extracellular space and the gradual saturation of the storage compartment. I find this hypothesis most attractive since the oscillations of free cytosol calcium may fit the phasicity of insulin release.

Another factor known to have a major impact on insulin secretion is cyclic AMP. In 1973 we and Grodsky's group discovered that glucose stimulates the accumulation of cyclic AMP in the islet [51, 52]. Extensive studies by my group demonstrated that this occurs prior to the initiation of insulin release, that its glucose dose-dependency is identical to that for insulin secretion, that stimulation or inhibition of hormone secretion is usually accompanied by similar changes in islet cyclic AMP, and that there exists a very tight correlation between the level of cyclic AMP and the insulin secretion rate [53-58]. These findings urged us to propose that cyclic AMP, together with cytosolic calcium, functions as the main controller of secretion. Of interest for understanding the basic defect in diabetes, in islets from hyperglycaemic Acomys, glucose failed to elevate the cyclic AMP con- 
centration as it failed to stimulate first-phase insulin secretion $[59,60]$.

There seems to be a definite link between the above two factors since on the one hand the glucose effect on cyclic AMP generation is calcium-dependent [61] and it has been shown that islet adenylate cyclase is stimulated by calcium-calmodulin [62], and, on the other, cyclic AMP has been thought to stimulate the mobilization of calcium from intracellular stores [63]. These interrelations may, however, be more complex than believed until now, as indicated by the work of Hellman et al. [48-50] and the description by Henquin and Meissner [64] of an action of endogenous cyclic AMP on plasma membrane calcium channels in islets. Today the consensus of opinion appears to be that calcium is the primary trigger of insulin release, while cyclic AMP merely acts as an amplifier of the secretory signal. I find it bothersome, however, that adequate insulin release is never obtained under conditions where glucose-induced cyclic AMP generation is diminished. As an example, the adenylate cyclase inhibitor RMI $12330(10$ $\mu \mathrm{mol} / 1)$, suppresses in parallel the effect of glucose on cyclic AMP generation and on insulin release in isolated rat islets [Y. Krausz and E. Cerasi, unpublished observations]. I am convinced that in the near future we will witness renewed interest in islet cyclic AMP metabolism, and possibly a modified view on the importance of this nucleotide for insulin release will emerge.

Are calcium ions and/or cyclic AMP responsible for the time-dependent effects of glucose on insulin secretion? No biochemical data are available on time-dependent inhibition. It is an attractive thought that the calcium-lowering effect of glucose described by Hellman et al. could be responsible for the reduced insulin response during time-dependent inhibition; this hypothesis has not yet been tested. We demonstrated that inhibition of glucose metabolism with mannoheptulose blocked time-dependent potentiation, whereas suppressors of insulin release, such as adrenaline, somatostatin or diazoxide had no effect $[34,38,39,65]$. We concluded therefore that metabolism of glucose was necessary for time-dependent potentiation. In contrast, removal of the calcium ion, and thus reduction of glucose-induced calcium uptake in the islet did not seem to modify timedependent potentiation [38], although conflicting data has been presented [66]. As to the effectuation of the amplificatory message of time-dependent potentiation on insulin release, neither glucose utilization nor glucose-induced cyclic AMP stimulation were augmented [38]. We assumed therefore that a distal step in the stimulus-secretion coupling must be involved in the amplification of the insulin response. I believe that the same is true for second-phase insulin release during prolonged stimulation, since cyclic AMP levels at this phase are not augmented [40]. Whether this discussion on the mechanism of time-dependent potentiation is valid for the correction of the diabetic insulin response from is- lets of Acomys is not known, since none of the mentioned studies were applied to islets from spiny mice.

Several studies suggest that calcium-sensitive proteins play an important role in the islet, since it was demonstrated that insulin secretion is sensitive to phenothiazines, and that the islet contains calmodulin [62, 67-69]. It is, thus, accepted that the calcium effects both on insulin release and cyclic AMP generation are mediated by calmodulin. However, recent findings cast some doubt that calmodulin is the only or the main mediator of the calcium effect. We studied the effects of two phenothiazine derivatives, trifluoroperazine which has high affinity for calmodulin, and promethazine with an affinity for calmodulin about $1 / 100$ that of trifluoroperazine [70]. During a $60-\mathrm{min}$ incubation with $16.7 \mathrm{mmol} / 1$ glucose, both drugs inhibited the insulin secretion. Surprisingly, however, the sensitivity of the islet was greater for promethazine than for trifluoroperazine ( ID $_{50} 5$ and $15 \mu \mathrm{mol} / 1$, respectively $[71$; Y. Krausz and E. Cerasi, unpublished observations]. These findings can be explained if one assumes that another calcium-sensitive protein, synexin, is active in the islet. Synexin is a 47000 dalton protein, isolated from the adrenal medulla and shown to induce aggregation of chromaffin granules and their binding to the cytosol membrane in the presence of calcium $[70,72,73]$. These studies have suggested that this protein may indeed be a key agent controlling the final steps of exocytosis. The demonstration that phosphatidyl inositol may act as the binding site for synexin [74], taken together with the importance of this lipid in the secretion event [75-78], certainly strengthens this assumption. Synexin is equally sensitive to inhibition by trifluoroperazine and promethazine at low micromolar concentrations, which distinguishes it from calmodulin, whose affinity for promethazine is in the range of 300-500 $\mu \mathrm{mol} / 1$ [ 70$]$.

We asked ourselves whether calcium-sensitive proteins are implicated in the phasic secretory pattern of the $\beta$-beta cell by having differential effects on first versus second-phase secretion. The high sensitivity of insulin secretion to inhibition by promethazine was demonstrated in prolonged static incubations $(60 \mathrm{~min})$ of islets [71]. When amounts of trifluoroperazine and promethazine equipotent in inhibiting second-phase release ( 15 and $5 \mu \mathrm{mol} / 1$ respectively) were used for first phase secretion studies (islets incubated at $16.7 \mathrm{mmol} / 1$ glucose for $5 \mathrm{~min}$ ) results were vastly different. Whilst trifluoroperazine induced a $100 \%$ inhibition of the effect of glucose on insulin release and on cyclic AMP generation, promethazine had no effect on either parameter [Y. Krausz and E. Cerasi, unpublished observations]. Although other interpretations are possible, we propose that the initial insulin response to glucose, which reflects mainly the acute stimulus-secretion coupling, is regulated by cyclic AMP and is highly sensitive to trifluoroperazine, thus suggesting that the action is mediated by calmodulin. Supersynexin, a protein related to synexin [79], also could be a candidate, since it is 
more sensitive to trifluoroperazine than to promethazine, and its high sensitivity to nanomolar concentrations of calcium may fit the time-courses of intracellular calcium during glucose stimulation. As to second-phase insulin response, the marked sensitivity to promethazine makes synexin the candidate of choice, the more so since with time glucose may raise the cytosol calcium concentration sufficiently to activate this protein [79]. It is clear from this discussion that in order to obtain a clear picture of the mechanisms that control insulin release in a timed manner, studies will have to be conducted on the presence of various calcium-sensitive proteins in islets from normal animals and diabetic models, on their biological activation or inhibition at various phases of secretion, taking into account the actual free calcium levels at these times and the possible interactions with cyclic AMP.

\section{New interests}

I have a deep liking for people who, at a respectable age, decide to leave diabetes research for, say, nephrology, or even better, car sales! I seem to have made a Catholic marriage with diabetes (remember, I live in the Holy Land), so this is how I will continue to justify my salary. Apart from studies that are continuations and extensions of the topics described above, three new areas give me the additional excitement needed at age 50 , and are briefly described below.

\section{Islet cultures}

We have recently succeeded in establishing a method for monolayer cultures of adult rat islet cells. These cultures are maintained on dishes coated with the extracellular matrix which apparently favours not only the attachment of islets and the migration of cells out of the islet to form a monolayer, but also the maintenance of functional integrity, since our cultures retain a normal sensitivity to glucose [N. Kaiser et al., unpublished observations]. The problem of fibroblast overgrowth has been solved by the use of an anti-fibroblast monoclonal antibody, cytotoxic in the presence of complement. Our present studies are concentrated on islet cell growth in response to cell damage induced by mechanical means as well as by islet cell antibodies from Type 1 diabetic subjects. In addition, I hope the system will reveal itself highly suitable to studies on cell surface receptors (e.g. the somatostatin receptor [71]) and to manipulation of the cell membrane composition.

\section{Regulation of glucose transport in skeletal muscle}

Muscle mass is certainly the prime target of insulin. Therefore when discussing insulin resistance, characterization of glucose uptake in muscle cells must be more relevant than studying monocytes or even adipocytes, convenient as they may be. We established a rat skeletal myoblast line (L8) to this end. Under appropriate conditions these cells undergo maturation and fuse into muscle fibres. We asked ourselves whether the post-receptor defect described in hyperglycaemic conditions could be due to "downregulation" of glucose transport by glucose itself. Indeed, cultures maintained at low glucose concentrations show a much higher rate of 2-deoxyglucose transport than those kept at high glucose. While the $\mathrm{Km}$ of the transport is identical in both conditions, the Vmax of the reaction is reduced by $50 \%$ at high glucose [S.Sasson and E.Cerasi, unpublished observations]. In this cell line, the set-point of the regulation is approximately $3 \mathrm{mmol} / 1$ glucose. Whether this reflects the situation in vivo or is related to the specific characteristics of this muscle cell line is under investigation. If valid for the situation in vivo, this model may explain why hyperglycaemia, as a secondary event, induces insulin resistance at the post-receptor level.

\section{Induction of glucose-sensitive insulin secretion in fibroblasts}

This is one of the most exciting projects that I have been involved with, and, barring misfortunes, will occupy my laboratory for considerable time. Rat islet genomic DNA was extracted and transferred, together with a thymidine kinase containing plasmid, into thymidine kinase deficient murine fibroblasts ( $\mathrm{L} \mathrm{tk}^{-}$cell line). By chosing appropriate conditions for DNA extraction and cell selection, we succeeded in obtaining fibroblasts that synthesize and secrete mature insulin to the medium in response to glucose [B. Klein et al., unpublished observations]. Thus, not only the insulin gene, but also all the genes that control the conversion of proinsulin to insulin, regulate the exocytotic event, and link the glucose stimulus to the secretion event, can be transferred to a heterologous non- $\beta$ mammalian cell. This work is in its infancy. Its potential is, however, tremendous, both from the viewpoint of basic science (recognition of the various genes that control the multiple steps of the stimulus-secretion coupling, of exocytosis, of cell surface receptors for various physiological modulators of insulin release; identification of genes that control the $\beta$-cell specific cell surface antigens, etc.), and perhaps from the viewpoint of a diabetologist (can one take fibroblasts from a diabetic, transfect them with, for example, pork islet DNA excluding the genes that induce the $64 \mathrm{~K}$ surface antigen [80], and transplant back the glucose-sensitive, insulin-producing autologous fibroblasts to the patient, thus preventing both graft rejection and attack of the transplant by the humoral and cellular autoimmunity of Type 1 diabetes?). I reserve the continuation of this topic for the 30th Anniversary Special Issue of Diabetologia!

Acknowledgments. I am indebted to all my collaborators and technicians in Stockholm, Geneva, Modena and Jerusalem for the immense 
pleasure they have provided me over the years. My very special appreciation and thanks to my present collaborators, Drs. R. Nesher, B. Klein, N. Kaiser and S.Sasson, to the staff of the Endocrinology Laboratories at Hadassah Hospital, and to my secretary L. Granot. I have been supported by too many agencies to name them all here. My sincere thanks to Yad Hanadiv Foundation, which is the main supporter of our present studies.

\section{References}

1. Cerasi E (1975) Mechanisms of glucose stimulated insulin secretion in health and in diabetes: some re-evaluations and proposals. Diabetologia 11: 1-3

2. Cerasi E, Luft R (1963) Plasma insulin response to sustained hyperglycaemia induced by glucose infusion in human subjects. Lancet 2:1359-1361

3. Olefsky JM, Kolterman OG (1981) Mechanism of insulin resistance in obesity and noninsulin-dependent (type II) diabetes. Am J Med 70: 151-168

4. Cerasi E, Nesher R (1985) Assessment of insulin secretion dynamics. In: Pohl SL, Larner J, Clarke WL (eds) Methods in diabetes research. John Wiley, New York (in press)

5. McCullough AJ, Miller LJ, Service FJ, Go VLW (1983) Effect of graded intraduodenal glucose infusions on the release and physiological action of gastric inhibitory polypeptide. J Clin Endocrinol Metab 56: 234-241

6. Cerasi E, Efendic S, Luft R (1973) Dose-response relationship of plasma insulin and blood glucose levels during oral glucose loads in prediabetic and diabetic subjects. Lancet 1:794-797

7. Kipnis DM (1968) Insulin secretion in diabetes mellitus. Ann Intern Med 69: 891-901

8. Nesher R, Tuch B, Hage C, Levy J, Cerasi E (1984) Time-dependent inhibition of insulin release: suppression of the arginine effect by hyperglycaemia. Diabetologia, 26: 142-145

9. Efendic S, Wajngot A, Cerasi E, Luft R (1980) Insulin release, insulin sensitivity, and glucose intolerance. Proc Natl Acad Sci USA 77: 7425-7429

10. Cerasi E, Luft R, Efendic S (1972) Decreased sensitivity of the pancreatic beta cells to glucose in prediabetic and diabetic subjects. A glucose dose-response study. Diabetes 21:224-234

11. Cerasi E, Nesher R, Litvin Y, Della Casa L (1983) Insulin resistance versus impaired insulin secretion in Type 2 (non-insulin-dependent) diabetes: predominance of the role of the pancreas. Diabetologia 25: 146 (Abstract)

12. Cerasi E, Luft R (1967) "What is inherited - what is added" hypothesis for the pathogenesis of diabetes mellitus. Diabetes 16: 615-627

13. Cerasi E, Luft R (1967) Plasma insulin response to glucose infusion in healthy subjects and in diabetes mellitus. Acta Endocrinol 55: $278-304$

14. Efendic S, Cerasi E, Elander I, Thornqvist C, Fick G, Berglund B, Luft R (1979) Studies on low insulin responders. Glucose tolerance and insulin response to intravenous and oral glucose challenges in 226 normal subjects and 25 subjects with mild or chemical diabetes. Acta Endocrinol (Suppl 224) 90: 5-32

15. Nordlander S, Ostman J, Cerasi E, Luft R, Ekelund LG (1973) Occurrence of diabetic type of plasma FFA and glycerol responses to physical exercise in prediabetic subjects. Acta Med Scand 193: 9-21

16. Cerasi E, Luft R (1974) Follow-up of non-diabetic subjects with normal and decreased insulin response to glucose infusion - first report. Horm Metab Res (Suppl 5) 113-120

17. Efendic S, Luft R, Wajngot A (1984) Aspects of the pathogenesis of Type 2 diabetes. Endocrinol Rev 5: 395 410

18. Kadowaki T, Miyake $Y$, Hagura $R$, Akanuma $Y$, Kajinuma $\mathrm{H}, \mathrm{Ku}-$ zuya N, Takaku F, Kosaka K (1984) Risk factors for worsening to diabetes in subjects with impaired glucose tolerance. Diabetologia 26: $44-49$

19. Srikanta S, Ganda OP, Gleason RE, Jackson RA, Soeldner JS,
Eisenbarth GS (1984) Pre-type I diabetes. Linear loss of beta cell response to intravenous glucose. Diabetes 33: 717- 720

20. Srikanta S, Ganda OP, Jackson RA, Brink SJ, Fleischnick E, Yunis E, Alper C, Soeldner JS, Eisenbarth GS (1984) Pre-Type 1 (insulin-dependent) diabetes: common endocrinological course despite immunological and immunogenetic heterogeneity. Diabetologia 27: 146-148

21. Cerasi E, Luft R (1967) Insulin response to glucose infusion in diabetic and non-diabetic monozygotic twin pairs. Genetic control of insulin response? Acta Endocrinol 55:330-345

22. Ohlsen P, Cerasi E, Luft R (1971) Glucose tolerance and insulin response to glucose in two large families with diabetic mothers in the first generation. Horm Metab Res $3: 1-5$

23. Cerasi E, Luft $R$ (1970) The occurrence of low insulin response to glucose infusion in children. Diabetologia 6: 85-89

24. Iselius L, Lindsten J, Morton NE, Efendic S, Cerasi E, Haegermark A, Luft R (1982) Evidence for an autosomal recessive gene regulating the persistence of the insulin response to glucose in man. Clin Genet 22: 180-194

25. Iselius L, Lindsten J, Morton NE, EfendicS, Cerasi E, Haegermark A, Luft R (1985) Genetic regulation of the kinetics of glucose-induced insulin release in man - Studies in families with diabetic and non-diabetic probands. Clin Genet (in press)

26. Ginsberg H, Kimmerling G, Olefsky JM, Reaven GM (1975) Demonstration of insulin resistance in untreated adult-onset diabetic subjects with fasting hyperglycemia. J Clin Invest 55: 454-461

27. Reaven GM, Doberne L, Greenfield MS (1982) Comparison of insulin secretion and in vivo insulin action in nonobese and moderately obese individuals with non-insulin-dependent diabetes mellitus. Diabetes 31: 382-384

28. De Fronzo RA, Deibert D, Hendler R, Felig P, Soman V (1979) Insulin sensitivity and insulin binding to monocytes in maturity-onset diabetes. J Clin Invest 63:939-946

29. Foley JE, Kashiwagi A, Verso MA, Reaven G, Andrews J (1983) Improvement in in vitro insulin action after one month of insulin therapy in obese noninsulin-dependent diabetics. J Clin Invest 72: 1901-1909

30. Wajngot A, Roovete A, Vranic M, Luft R, Efendic S (1982) Insulin resistance and decreased insulin response to glucose in lean Type 2 diabetics. Proc Natl Acad Sci USA 79: 4432-4436

31. Revers RR, Fink R, Griffin J, Olefsky JM, Kolterman OG (1984) Influence of hyperglycemia on insulin's in vivo effects in type II diabetes. J Clin Invest 73: 664-672

32. Gutzeit A, Renold AE, Cerasi E, Shafrir E (1979) Effect of diet-induced obesity on glucose and insulin tolerance of a rodent with a low insulin response (acomys cahirinus). Diabetes $28: 777-784$

33. Cerasi E (1975) Feed-back inhibition of insulin secretion in subjects with high and low insulin response to glucose. Diabetes Metab 1: 73-76

34. Efendic S, Lins PE, Cerasi E (1979) Potentiation and inhibition of insulin release in man following priming with glucose and with arginine - effect of somatostatin. Acta Endocrinol 90:259-271

35. Nesher R, Waldman L, Cerasi E (1984) Time-dependent inhibition of insulin release: glucose-arginine interactions in the perfused rat pancreas. Diabetologia 26: 146-149

36. Grodsky GM, Curry D, Landhl H, Bennett LL (1969) Further studies on the dynamic aspects of insulin release in vitro with evidence for a two-compartmental storage system. Acta Diab Lat (Suppl 1) 6:554-579

37. Cerasi E (1975) Potentiation of insulin release by glucose in man. I. Quantitative analysis of the enhancement of glucose induced insulin secretion by pretreatment with glucose in normal subjects. Acta Endocrinol 79: 483-501

38. Grill V, Adamson U, Cerasi E (1978) Immediate and time-dependent effects of glucose on insulin release from rat pancreatic tissue. Evidence for different mechanisms of action. J Clin Invest 61: 1034-1043

39. Grill V, Adamson U, Rundfeldt M, Andersson S, Cerasi E (1979) Glucose memory of pancreatic $B$ and $A_{2}$ cells. J Clin Invest 64: 700-707

40. Cerasi E (1981) Differential actions of glucose on insulin release: 
re-evaluation of a mathematical model. In: Cobelli C, Bergman $\mathrm{RN}$ (eds) Carbohydrate metabolism. John Wiley and Sons, London, pp 3-24

41. Perley MJ, Kipnis DM (1967) Plasma insulin responses to oral and intravenous glucose: studies in normal and diabetic subjects. $J$ Clin Invest 46: 1954-1962

42. Seltzer HS, Allen EW, Herron A, Brennan MT (1967) Insulin secretion in response to glycemic stimulus: relation of delayed initial release to carbohydrate intolerance in mild diabetes. J Clin Invest $46: 323-335$

43. Rabinovitch A, Gutzeit A, Renold AE, Cerasi E (1975) Insulin secretion in the spiny mouse (Acomys cahirinus). Dose and time kinetic studies with glucose in vivo and in vitro. Diabetes 24: $1094-1100$

44. Cerasi E (1975) Potentiation of insulin release by glucose in man. III. Normal recognition of glucose as a potentiator in subjects with low insulin response and in mild diabetes. Acta Endocrinol 79: 511-534

45. Nesher R, Abramovitch E, Cerasi E (1985) Correction of diabetic pattern of insulin release from islets of the spiny mouse (Acomys cahirinus) by glucose priming in vitro. Diabetologia $28: 233-236$

46. Rahier J, Goebbels RM, Henquin JC (1983) Cellular composition of the human diabetic pancreas. Diabetologia 24:366-371

47. Wollheim CB, Sharp GWG (1981) Regulation of insulin release by calcium. Physiol Rev 61: 914-973

48. Rorsman P, Berggren PO, Gylfe E, Hellman B (1983) Reduction of the cytosolic calcium activity in clonal insulin-releasing cells exposed to glucose. Biosci Reports 3: 939-946

49. Rorsman P, Abrahamsson H, Gylfe E, Hellman B (1984) Dual effects of glucose on the cytosolic $\mathrm{Ca}^{2+}$ activity of mouse pancreatic B-cells. FEBS Lett 170: 196-200

50. Hellman B (1985) $\beta$-cell cytoplasmic $\mathrm{Ca}^{2+}$ balance as a determinant for glucose-stimulated insulin release. Diabetologia 28: 494-501

51. Grill V, Cerasi E (1973) Activation by glucose of adenyl cyclase in pancreatic islets of the rat. FEBS Lett 33:311-314

52. Charles MA, Fanska R, Schmid FG, Forsham PH, Grodsky GM (1973) Adenosine 3',5'-monophosphate in pancreatic islets: Glucose-induced insulin release. Science 179: 569-571

53. Grill V, Cerasi E (1974) Stimulation by D-glucose of cyclic adenosine $3^{\prime}: 5^{\prime}$-monophosphate accumulation and insulin release in isolated pancreatic islets of the rat. J Biol Chem 249:4196-4201

54. Grill V, Cerasi E (1976) Effect of hexoses and mannoheptulose on cyclic AMP accumulation and insulin secretion in rat pancreatic islets. Biochim Biophys Acta 437: $36-50$

55. Grill V, Cerasi E (1978) Interacting effects of sulfonylureas and glucose on cyclic AMP metabolism and insulin release in pancreatic islets of the rat. J Clin Invest 61: 1346-1354

56. Grill V, Asplund K, Hellerstrom C, Cerasi E (1975) Decreased cyclic AMP and insulin response to glucose in isolated islets of neonatal rats. Diabetes 24: 746-752

57. Rabinovitch A, Grill V, Renold AE, Cerasi E (1976) Insulin release and cyclic AMP accumulation in response to glucose in pancreatic islets of fed and starved rats. J Clin Invest 58: 1209-1216

58. Rabinovitch A, Cerasi E, Sharp GWG (1978) Adenosine 3'-5'-monophosphate-dependent and -independent inhibitory effects of epinephrine on insulin release in rat pancreatic islets. Endocrinology 102: 1733-1739

59. Rabinovitch A, Gutzeit A, Grill V, Kikuchi M, Renold AE, Cerasi E (1975) Defective insulin secretion in the spiny mouse (Acomys cahirinus). Possible value in the study of the pathophysiology of diabetes. Isr J Med Sci 11: 730-737

60. Grill V, Cerasi E (1979) The metabolism of cyclic AMP and glucose in isolated islets from Acomys cahirinus. Diabetologia 16: $47-50$

61. Karl RC, Zawalich WS, Ferendelli JA, Matschinsky FM (1975) The role of $\mathrm{Ca}^{++}$and cyclic adenosine $3^{\prime}-5^{\prime}$-monophosphate in insulin release induced in vitro by the divalent cation ionophore A23187. J Biol Chem 250: 4575-4579
62. Valverde I, Vandermeers A, Anjaneyulu R, Malaisse WJ (1979) Calmodulin activation of adenylate cyclase in pancreatic islets. Science 206: 225-227

63. Kikuchi M, Wollheim CB, Siegel EG, Renold AE, Sharp GWG (1979) Biphasic insulin release in rat islets of Langerhans and the role of intracellular $\mathrm{Ca}^{++}$stores. Endocrinology 105: 1013-1019

64. Henquin JC, Meissner HP(1984) The ionic, electrical, and secretory effects of endogenous cyclic adenosine monophosphate in mouse pancreatic B cells: studies with forskolin. Endocrinology 115: $1125-1134$

65. Cerasi E (1975) Potentiation of insulin release by glucose in man. II. Role of the insulin response and enhancement of stimuli other than glucose. Acta Endocrinol 79: 502-510

66. Ashby JP, Shirling D (1980) Evidence for priming and inhibitory effect of glucose on insulin secretion from isolated islets of Langerhans. Diabetologia 18: 417-421

67. Sugden MC, Christie MR, Ashcroft SJH (1979) Presence and possible role of calcium-dependent regulator (calmodulin) in rat islets of Langerhans. FEBS Lett 105: 95-100

68. Krausz Y, Wollheim CB, Siegel E, Sharp GWG (1980) Possible role for calmodulin in insulin release. Studies with trifluoroperazine in rat pancreatic islets. J Clin Invest 66: 603-607

69. Christie MR, Ashcroft SJH (1984) Cyclic AMP-dependent protein phosphorylation and insulin secretion in intact islets of Langerhans. Biochem J 218: 87-99

70. Pollard HB, Scott JH, Creutz CE (1983) Inhibition of synexin activity and exocytosis from chromaffin cells by phenothiazine drugs. Biochem Biophys Res Commun 113: 908-915

71. Sussman KE, Pollard HB, Leitner JW, Nesher R, Adler J, Cerasi E (1983) Differential control of insulin secretion and somatostatinreceptor recruitment in isolated pancreatic islets. Biochem J 214: $225-230$

72. Creutz CE, Pazoles CJ, Pollard HB (1979) Self-association of synexin in the presence of calcium. Correlation with synexin-induced membrane fusion and examination of the structure of synexin aggregates. J Biol Chem 254: 553-558

73. Creutz CE, Sterner DC (1983) Calcium dependence of the binding of synexin to isolated chromaffin granules. Biochem Biophys Res Commun 114: 355-364

74. Hong K, Duzgunes N, Papahadjopoulos D (1982) Modulation of membrane fusion by calcium-binding proteins. Biophys $\mathrm{J} 37$ : 297-305

75. Hotchkiss A, Pollard HB, Scott J, Axelrod J (1981) Release of arachidonic acid from adrenal chromaffin cell cultures during secretion of epinephrine. Fed Proc 40: 256 (Abstract)

76. Metz S, Van Rollins M, Strife R, Fujimoto W, Robertson RP (1983) Lipoxygenase pathway in islet endocrine cells. Oxidative metabolism of arachidonic acid promotes insulin release. J Clin Invest 71: 1191-1205

77. Laychock SG (1983) Fatty acid incorporation into phospholipids of isolated pancreatic islets of the rat. Relationship to insulin release. Diabetes 32: 6-13

78. Evans MH, Pace CS, Clements RS (1983) Endogenous prostaglandin synthesis and glucose-induced insulin secretion from the adult rat pancreatic islet. Diabetes 32: 509-515

79. Pollard HB (1985) Synexin in review. Vitam Horm (in press)

80. Baekkeskov S, Nielsen JH, Marner B, Bilde T, Ludvigsson J, Lernmark A (1982) Autoantibodies in newly diagnosed diabetic children immunoprecipitate human pancreatic islet cell proteins. Nature 298: $167-169$

\section{Prof. Erol Cerasi}

Department of Endocrinollogy and Metabolism

Hadassah University Hospital

91120 Jerusalem

Israel 